\section{ESPRAIAMENTO DISCURSIVO DA CULTURA DO FITNESS NA CONTEMPORANEIDADE}

\author{
TODAY'S DISCURSIVE EXPANSION OF THE FITNESS CULTURE
}

\author{
EXPANSION DISCURSIVA DE LA CULTURA DEL FITNESS EN LA \\ CONTEMPORANEIDAD
}

\section{Maria Simone Vione Schwengber*, Caterine de Moura Brachtvogel*, Rodrigo Saballa de Carvalho**}

\begin{abstract}
Palavras chave: Corpo humano. Construção social da identidade. Estilo de vida.

Resumo: A emergência da cultura do fitness na contemporaneidade mostra-se como um espaço discursivo que se espraia, produzindo certa memória social. A partir dessa percepção, questionamos: quais são as condições de emergência do espraiamento da cultura do fitness? Para pensar essas condições, utilizamos alguns dos rastros históricos de emergência de inspiração foucaultiana, o que nos conduziu na construção teóricometodológica do artigo. Apontamos como resultados que: os discursos fitness se gestam na linguagem contemporânea por relações de saber-poder da positividade da vida e dos corpos; a biopolítica, por meio da operação dos argumentos da produção muscular (exercício corporal), cria-produz "efeitos de verdades" associados ao desenvolvimento do capitalismo e do consumo, o que tem gerado uma nova economia política do discurso do fitness, valendo-se de um lugar moral identitário - ser fitness, em um trabalho sobre si, testemunha de valores de vigor, saúde, força de vontade, controle.
\end{abstract}

Keywords: Human body. Social construction of identity. Life style.

\begin{abstract}
The fitness culture emerging in today's world is an expanding discursive space that produces certain social memory. Based on this perception, we ask: what are the conditions for the expansion of fitness culture? Focusing on these conditions, we used some historical traces of emergence proposed by Foucault to guide us in the theoreticalmethodological construction of this paper. Findings included: fitness discourses have been generated in contemporary language by power-knowledge relations for positivity of life and bodies; bio-politics, by operating with the arguments of muscle production (physical exercises), creates-produces "effects of truth" associated with the development of capitalism and consumption, thus producing a new political economy of the fitness discourse with the use of an identity moral place - being fitness, in a work on oneself, bear witness to values of vigor, health, willpower, and control.
\end{abstract}

\section{Palabras clave:} Cuerpo humano. Construcción social de la identidad. Estilo de vida.
Resumen: La emergencia de la cultura fitness en la contemporaneidad se muestra como un espacio discursivo que se expande, produciendo cierta memoria social. A partir de esta percepción, cuestionamos: ¿Cuáles son las condiciones de emergencia de la expansión de la cultura del fitness? Para pensar esas condiciones, utilizamos algunos de los rastros históricos de emergencia de inspiración foucaultiana, lo que nos condujo en la construcción teórico-metodológica del artículo. Señalamos como resultados que: los discursos fitness se gestan en el lenguaje contemporáneo por relaciones de saber-poder de la positividad de la vida y de los cuerpos; la biopolítica, por medio de la operación de los argumentos de la producción muscular (ejercicio corporal), crea-produce "efectos de verdades", asociados al desarrollo del capitalismo y del consumo, lo que ha generado una nueva economía política del discurso del fitness, valiéndose de un lugar moral identificador — ser fitness, en un trabajo sobre sí, representa valores de vigor, salud, fuerza de voluntad, control.
* Universidade Regional do Noroeste do Estado do Rio Grande do Sul. ljuí, RS, Brasil.

E-mail: simone@ unijui.edu.br; cati-mb@ hotmail.com

** Universidade Federal do Rio Grande do Sul. Porto Alegre, RS, Brasil. E-mail: rsaballa@ @erra.com.br

Recebido em: 22/05/2018 Aprovado em: 31/10/2018

DOI: https://doi.org/10.22456/1982-8918.83071 (c) (1) (8) Licence 


\section{ESPRAIAMENTO DA EXPRESSÃO FITNESS}

O termo espraiamento deriva do verbo espraiar, que significa estender-se, irradiar-se, lançar-se. Espraiamento, quando pensado na perspectiva geográfica, pode significar até onde os rios e mares alcançam e ampliam as margens, criando linhas; também significa aquilo que se espalha para quase todos os lados (ESPRAIAR, 2018). Escolhemos esse termo para pensar justamente a difusão da expressão fitness, pois, em uma pesquisa na internet, encontramos um conjunto desse enunciado discursivo na rede.

Essa pesquisa na internet (2018) foi realizada no site de buscas Google. Tendo como critério de procura a expressão fitness, localizamos inicialmente 6.505 enunciados. Sem fins de categorização, apresentamos, no Quadro 1, abaixo, alguns desses enunciados, como forma de dar visibilidade à quantidade de discursos presentes na internet vinculados à cultura fitness.

Quadro 1 - Pesquisa da expressão fitness na internet.

\begin{tabular}{|c|}
\hline 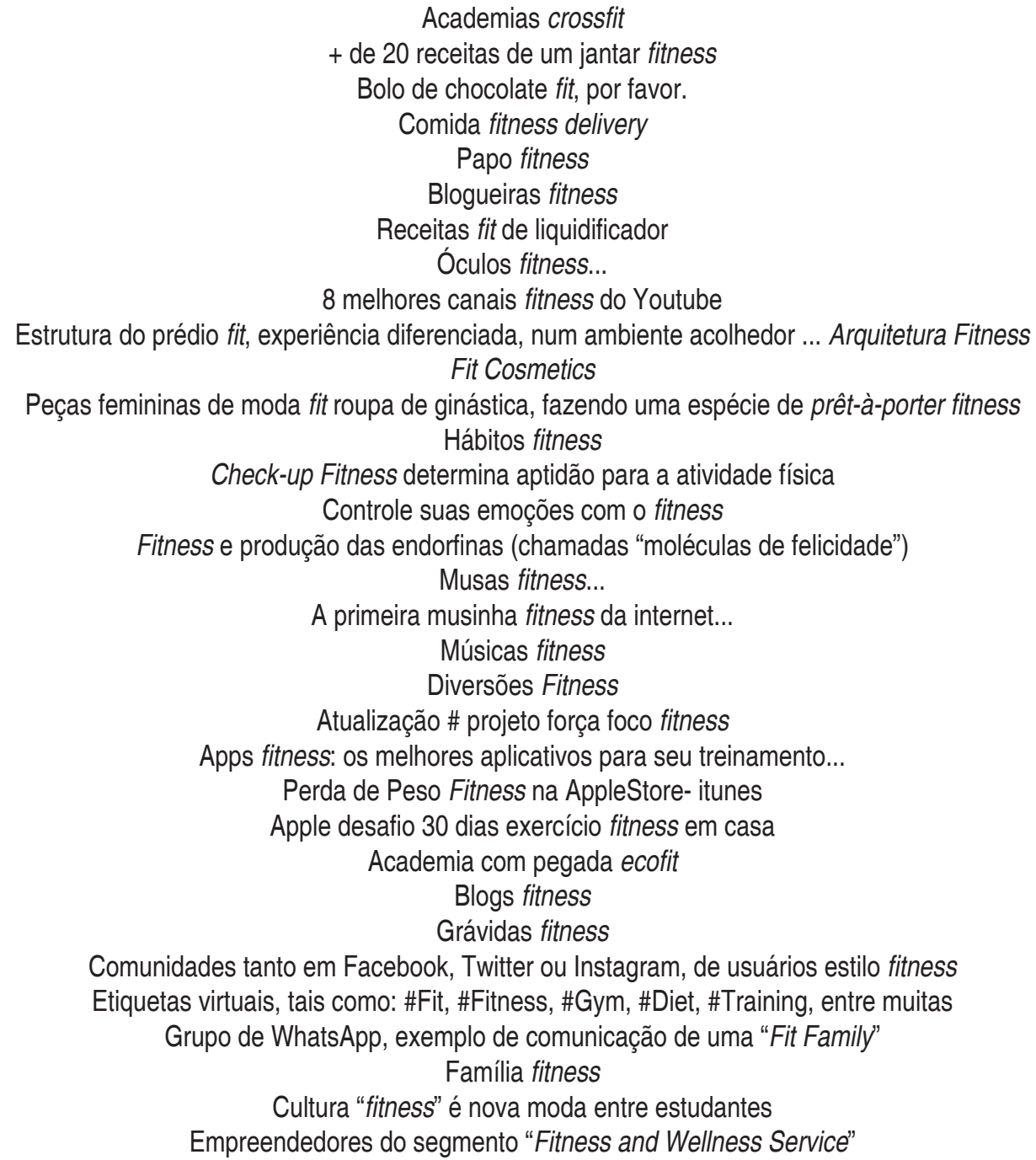 \\
\hline
\end{tabular}

Fonte: Elaborado pelos autores a partir de buscas Google (2018).

Essa pesquisa nos permite afirmar que há um espraiamento da expressão fitness, uma espécie de proliferação discursiva que vai além do campo da Educação Física, englobando também moda, arquitetura, alimentação, economia, cultura e sociedade. Em tal perspectiva, 
tomamos o discurso (FOUCAULT, 2004a) sobre o fitness como categoria de análise, tendo em vista compreender as relações que compõem as comunidades de fala dentro de determinado campo discursivo. Com isso, destacamos que a natureza social do discurso exerce a função de "política discursiva", a qual é reativada a cada nova nomeação (FOUCAULT, 2004a).

A linguagem é um dos conceitos estruturadores dos discursos e das relações do humano com o mundo social e cultural. Por essa razão, referimo-nos à materialidade objetiva da linguagem na qual o sujeito está submetido, no sentido de sua produção subjetiva, pensando sobre os diferentes modos pelos quais os seres humanos se tornam sujeitos, produzindo-se como efeito de discursos (FOUCAULT, 2004a). Salientamos que a formação de um discurso pode ser entendida como prática de produção de sentidos para os sujeitos, implicando variadas possibilidades de produções subjetivas. Nesse contexto, apontamos aqui as formações discursivas vinculadas à expressão fitness.

Cabe ressaltar que compreendemos as formações discursivas como mediadoras de práticas sociais (FOUCAULT, 2004a). Isso denota que a inscrição de um discurso é construída localmente, a partir de contingências políticas, culturais, institucionais e históricas que situam as práticas discursivas. As formações discursivas referentes ao fitness, por exemplo, alcançam quase todos os sujeitos, até mesmo os não adeptos desse imperativo de "culto ao corpo".

Considerando o exposto, afirmamos de antemão que, metodologicamente, não buscamos uma suposta origem da expressão fitness, mas abrimos espaços para pensarmos a proveniência dos rastros, nomeações e formações discursivas do fitness (FOUCAULT, 2004a). Por isso, no presente texto, problematizaremos discursos e práticas, no intuito de destacar o jogo de produção do movimento fitness.

Tal inspiração metodológica advém das pesquisas genealógicas realizadas por Foucault (1979), como modo de proceder em uma investigação histórica que parte de uma questão do presente. Então, podemos alegar que, mesmo se o presente é objeto último da investigação, a busca no passado não significa uma tentativa de compreender o presente tendo em conta as razões do passado, já que este não representa um espaço preservado que possibilitaria descobrir verdades até aquele momento desconhecidas. Nesse caso, o dito por Foucault (1979, p. 21), quando afirma que a genealogia não pretende voltar no tempo para estabelecer novamente uma grande "continuidade para além da dispersão do esquecimento", confirma nossa escolha metodológica.

Assim, contemporaneamente, as formações discursivas a respeito do fitness têm ganhado popularidade no campo dos exercícios, academias, alimentação, suplementos, dietas, bebidas, controle das emoções, eventos, conversas e aplicativos, até diversões, músicas, hábitos e modos de vestir, de comer, de socializar. Isso indica que há um portfólio de produtos, serviços e modos de ser associado ao fitness, tendência que tem se expandido e se generalizado como uma espécie de cultura-mundo, expressão que tomamos emprestada de Lipovetsky e Serroy (2011).

Para os referidos autores, cultura-mundo significa uma universalização que se apodera das esferas da vida social e vai massificando os modos de existência, a partir de movimentos constitutivos de um ethos (LIPOVETSKY; SERROY, 2011). Nesse contexto, argumentamos que tem sido possível perceber a produção de uma cultura do fitness como uma cultura-mundo (LIPOVETSKY; SERROY, 2011). 
Portanto, os discursos sobre a importância do fitness têm se configurado como parte de um ciclo histórico, de determinado tempo, sendo sustentado por relações de saber-poder (FOUCAULT, 2004b). Por isso, a intensidade da cultura do fitness nos provoca a indagar: quais são as condições de emergência do espraiamento discursivo da cultura do fitness? Para apresentarmos a emergência da cultura do fitness, inspirados em Foucault (1979, 2000), definimos dois objetivos centrais para a discussão a ser exposta no artigo:

a) apresentar as condições de emergência da cultura do fitness e sua constituição histórica;

b) destacar alguns dos efeitos de sentido produzidos pelos discursos da cultura do fitness que corroboram seu espraiamento.

Inspirados metodologicamente em Foucault (1979) no que tange a seus estudos genealógicos, procuraremos evidenciar, em nossas análises, como se constroem as possibilidades dos discursos relativos à cultura do fitness em meio às relações de saber-poder que caracterizam e legitimam o que é considerado verdadeiro no tempo presente. Julgamos conveniente ressaltar que tal modo foucaultiano de compreensão da história se deve às influências que o filósofo recebeu de suas leituras de Nietzsche. Uma dessas influências foi a utilização da genealogia como modo de proceder em seus estudos históricos.

Dessa forma, Foucault (1979), inspirado em Nietzsche, propôs uma abordagem da História que recusa a busca da origem (Ursprung) - entendida como começo nobre, local onde estaria oculto o sentido do passado, momento em que tudo começou, lugar de pureza, perfeição e verdade. Para tanto, o filósofo investe contra a noção de totalidade e necessidade, voltando-se para o jogo fortuito das dominações que constituem os acontecimentos. Devido a esse investimento, Foucault (1979) retoma passagens de Nietzsche e apresenta a genealogia como proveniência (Herkunft) e emergência (Entestehung), contribuindo para que se pense na constituição histórica de certos discursos, como o da cultura do fitness.

Assim, discutiremos no decorrer do texto as condições de possibilidade que incidiram no espraiamento discursivo da cultura do fitness na contemporaneidade.

\section{A EMERGÊNCIA DA CULTURA DO FITNESS COMO POLÍTICA DOS SABERES}

Desafiamo-nos a pensar na emergência da cultura do fitness e no conjunto de estratégias que incidem na sua popularização por meio da constituição de um ethos. Como delineamento inicial da emergência do fitness, ponderamos sobre os rastros do fitness e de sua cultura, que se fortaleceu na modernidade a partir da positividade da vida e dos corpos. Corroborando o argumento, Foucault (1988) afirma que os séculos XIX e XX marcaram as sociedades ocidentais com novos tipos de saberes, produzindo uma espécie de mentalidade da época que sobrevaloriza a vida física e mental sob a alcunha de saúde.

Podemos identificar, na modernidade, uma transformação no campo das políticas, das práticas e das técnicas que marcaram os diversos fenômenos da vida humana, na ordem dos saberes e dos poderes, sobre os corpos dos sujeitos. Assim, pela primeira vez na história, "0 biológico refletiu-se no político" (FOUCAULT, 2000, p. 134), implicando uma ruptura "no regime do discurso científico e sobre os modos pelos quais a dupla problemática da vida e do humano veio atravessar e redistribuir a ordem da episteme clássica" (FOUCAULT, 2000, p. 134). Além disso, houve uma intensificação e "proliferação das políticas e das tecnologias" (FOUCAULT, 2000 , p. 135) e controle e produção dos corpos dos indivíduos. 
Ambas as transformações propiciaram investimentos nos corpos, na saúde e nos cuidados na condução da vida. Tratavam-se de investimentos que visavam "intervir nas condições de vida das pessoas, para modificá-las e impor-lhe normas" (FOUCAULT, 1997, p. 86). Nesse sentido, Foucault (1988, p. 134) declara que biopolítica designa "o que faz com que a vida e seus mecanismos entrem no domínio dos cálculos explícitos, e faz do poder saber um agente de transformação da vida humana".

Em tal perspectiva, os termos biopoder e biopolítica passam a ser pensados por Foucault $(1988,2008 a)$ no contexto histórico e político da modernidade, no qual se sobressai a emergência de políticas sobre a vida da população, às quais contemporaneamente o fitness pode ser vinculado. Entendemos a biopolítica como uma tecnologia que procura controlar a probabilidade de eventos vinculados com controle da vida e dos corpos (FOUCAULT, 1997, 1988, 2008a). Para tanto, a biopolítica se utiliza de conhecimentos produzidos, tendo em vista a intensificação da produtividade dos corpos (FOUCAULT, 2008a) de modo sutil e econômico.

Foucault (2008b) alerta para a emergência de certos tipos de práticas governamentais, e exige-nos um novo olhar sobre o que regula e governa a vida, tanto individual quanto coletiva. Esse argumento nos instiga a pensar a constituição de uma arte de governo em um sentido amplo de práticas e técnicas destinadas a dirigir e conduzir as condutas dos sujeitos (FOUCAULT, 2008b). Destacam-se as conexões estabelecidas entre os princípios de ação política e os que pretendem dirigir a conduta social. Nesse caso, o governamento dos corpos traduz-se na seguinte questão: como cuidar de si mesmo buscando uma vida saudável e qualitativamente rentável enquanto força produtiva?

Essa dimensão do cuidar do si, na contemporaneidade, atua em duas dimensões - no coletivo, sob uma perspectiva governamental, e no individual, com diversas formas sutis de incitação ao governo de condução das condutas de si (FOUCAULT, 2008a). Nesse sentido, os sujeitos, instigados a cuidarem de si, pela primeira vez na história, têm de produzir sua existência e manter seus corpos fisicamente ativos, aptos, saudáveis (FOUCAULT, 2004a). Isso implica perceber que os processos de cuidado em torno da promoção da saúde são uma importante "estratégia biopolítica" (FOUCAULT, 1997), realçando que há certos modos de vida mais saudáveis do que outros, imprimindo um novo valor sobre os modos de existência, com base nos critérios de um pretenso saber científico, e não nas referências singulares dos sujeitos.

Nesse processo de cuidados, práticas e técnicas, a racionalização ocidental teve um profundo impacto nos saberes sobre os corpos e, por consequência, nos modos de conduzir a vida. Foi no contexto da modernidade que os corpos passaram a ser olhados como uma instrumentalidade racional pelos diferentes saberes e foram propostas outras formas de olhar os corpos, olhares que são direcionados para o seu interior, nas características físicas, dos músculos e também dos órgãos vitais (TURNER, 2004). Corroborando os argumentos expostos, Turner (2004) aponta a importância dos Cadernos Anatômicos de Leonardo da Vinci (Leonardo on the Human Body), os quais resultaram dos desenhos de da Vinci de órgãos, músculos e elementos dos sistemas anatomofuncionais do corpo humano ao longo de 15 anos (de 1498 a 1513).

A partir desse movimento, Andreas Vesalius, considerado o "pai da anatomia", publicou o livro De Humani Corporis Fabrica, em 1543, uma obra que marcou a fase inicial dos estudos modernos sobre anatomia (TURNER, 2004). O sistema musculoesquelético e suas imagens 
começaram a ter valor educativo, incidindo na divulgação do trabalho muscular dos corpos. Nessa direção, a emergência da exaltação dos músculos e as reverberações do trabalho muscular foram assim engendrando a cultura do fitness.

Prosseguindo a discussão, para Courtine (1995), forja-se na modernidade um culto ao corpo, um olhar para a aparência, com foco no desenvolvimento dos músculos. Instituiu-se, dessa maneira, pouco a pouco, a ideia de um corpo que é individual e trabalhado. Os músculos tornaram-se um dos símbolos mais apelativos do trabalho sobre si. Passou a ocorrer uma expansão cada vez mais positiva dos exercícios musculares, fornecendo bases norteadoras, como um estímulo para "o autogoverno ativo do corpo para dele extrair força e energia para vida" (COURTINE, 1995, p. 90), de modo que se popularizaram os enunciados sobre o fitness. As percepções científicas dos saberes anatômicos desencadearam, no século XIX, a noção da dinâmica dos corpos - exercícios musculares -, fortalecendo a construção da ideia de que os corpos podem ser qualificados/modificados por meio de intervenções e de técnicas específicas do trabalho muscular. Tal noção esteve implicada na profusão dos discursos sobre a importância de manutenção de uma vida ativa.

A esse respeito, Courtine (1995) afirma que a obsessão com os exercícios físicos no século XX ocorreu em função do ideal de modelagem muscular dos corpos. Para o autor, um corpo considerado trabalhado seria aquele que demonstra disciplina e força de vontade, ou seja, que comprova "os investimentos sobre si, [a partir de seu] testemunho de vigor, saúde, força, e moral resultante de um trabalho sobre si" (COURTINE, 1995, p. 91).

Isso significa que trabalhar o corpo se associa aos exercícios físicos e musculares e, por consequência, às práticas da Educação Física, relacionando-se aos vários tipos de treinamento existentes. A valorização moderna do corpo musculoso como demonstração de uma força moral produz um efeito nos sujeitos e na forma como estes constituem seus condicionamentos físicos (COURTINE, 1995). O trabalho muscular, então, é visto como um efeito do esforço dos sujeitos, de um corpo que vai se construir com uma dedicação contínua. Recorremos a Vigarello (2008) para reiterar essa proposição, quando afirma que a centralidade do trabalho muscular é o movimento, a repetição, a insistência, e que isso sinaliza uma certa pedagogia corporal.

Entendemos que há uma elaboração simbólica dos músculos na cultura e conectamos isso a outro rastro da emergência da cultura do fitness. 0 saber fitness apoia-se inicialmente nos estudos da fisiologia, como aponta Corbin (2008); as formulações científicas postulam que os músculos constituem um importante componente corporal, pois ajudam a manter a temperatura interna, bem como a estrutura óssea mais densa. Esse saber, mais tarde, vai associar-se à ideia do bodybuilding 1 , no sentido de construção de corpos delineados.

À medida que as práticas e os saberes científicos avançam, no século XX, o discurso da importância do exercício muscular cresce e confere suporte à produção e difusão de discursos (FOUCAULT, 2004b) sobre a importância de uma vida ativa e saudável por meio da prática de exercícios físicos. Assim, a "vontade de saber" do discurso da cultura do fitness torna-se cada vez mais determinada por parâmetros dos discursos fisiologistas e médicos acerca da capacidade física muscular. O funcionamento cardiorrespiratório, do coração e dos pulmões, é capacitado a partir da prática regular de exercícios aeróbios e de musculação. 0 embasamento

1 Bodybuilding, no sentido etimológico da palavra, é a junção dos termos body (corpo) e building (construção); então, é a construção do corpo, e o termo é traduzido como musculação. Normalmente, o termo bodybuilding é utilizado para intitular a modalidade esportiva praticada por quem é fisiculturista e compete no esporte que leva o mesmo nome (BRACHTVOGEL, 2017). 
científico dos discursos circulantes da cultura do fitness é reforçado pelo discurso da fisiologia médica.

Nesse ínterim, os saberes emergentes do fitness fortaleceram-se e ampliaramse, conforme o termo foi reafirmado pela Organização Mundial da Saúde em 1975 como capacidades físicas conducentes a uma boa saúde. A esse respeito, Foucault (2004b) ensinanos que os saberes sedimentam a produção de verdades e posições de sujeitos, incidindo nos modos de funcionamento da sociedade.

Portanto, podemos afirmar que a promoção da cultura do músculo ocorre por meio e por consequência dos exercícios físicos e da emergência de uma "cultura do fitness". Tal cultura do fitness teve um fortalecimento no Brasil no século XX (FURTADO, 2009), com a criação de determinados espaços, inicialmente nomeados como Institutos de Modelação Física, Centros de Fisiculturismo, Clubes de Calistenias e Ginásios, até o aparecimento das contemporâneas Academias de Musculação, com base ou não no culturismo ou fisiculturismo.

Assim, a prática do exercício muscular no século XX ganhou destaque associado à produção de um estilo de vida ativo e à qualidade de vida. A sarcopenia (redução progressiva da massa muscular) vem sendo discutida contemporaneamente nos diversos âmbitos do desenvolvimento humano e mais precisamente no que tange à importância do exercício físico no envelhecimento (VARELLA, 2017). Estudos colaboram para uma nova "política de verdade" científica (FOUCAULT, 2000) no século XXI sobre os benefícios das práticas da musculação, 0 que acentua a visibilidade do trabalho muscular na produção de sujeitos exercitantes.

Nessa perspectiva, Sabino (2000) destaca em seus estudos que a emergência das imagens dos corpos musculosos, nos séculos XX e XXI, em sua erotização discursivoimagética, cinematográfica, musical e novelesca, relacionada aos crescentes espaços e práticas emergentes da indústria do entretenimento, impulsionou a modelagem e a produção da "cultura do fitness". Foucault (2004a) ajuda-nos a problematizar o quanto a emergência desse tipo de discurso é permeada por relações de saber-poder que a produzem. Isso porque os discursos não são simplesmente aquilo que traduz as lutas ou sistemas de dominação.

Dessa forma, o discurso, conforme assegura Foucault (2004a), não se apresenta apenas como código técnico de saberes, mas produz e fornece no que tange às posições de sujeito. Isso indica que o sujeito é produzido nas malhas discursivas de uma dada cultura e contexto histórico (FOUCAULT, 2004a). Ou seja, é ingenuidade pensarmos que a proliferação discursiva da cultura do fitness ocorre somente em virtude da dimensão biológica (músculos); defendemos que se encontra também inteiramente vinculada a efeitos sociais, políticos e culturais de "produção" de sujeitos fitness.

\section{OS EFEITOS DE SENTIDO DO DISCURSO SOBRE A CULTURA DO FITNESS}

A partir da discussão apresentada até o momento, destacamos que é em torno de certos padrões e valores de corpos magros, tonificados e trabalhados que a cultura do fitness se associa, representando sujeitos com vitalidade, saúde, controle, poder, utilidade. Ser "frango" ou sarado, franzino ou "monstro"2 dizem respeito não só à forma física, mas a modos

\footnotetext{
2 Frango e monstro são gírias normalmente utilizadas por frequentadores assíduos de academias de musculação. Frango seria aquele sujeito magrinho, de pequena estrutura, com pouco desenvolvimento de massa muscular. Porém, o termo frango está sendo utilizado para designar comportamento e aspecto psicológico, caracterizando o sujeito que finge estar treinando e tem atitudes de "galinhagem", brincadeira, não levando o treino a sério. Já o termo monstro seria usado para chamar aquele sujeito que treina e fica com um grande volume de massa muscular (BRACHTVOGEL, 2017).
} 
de subjetivação. Assim, supomos que há correlações de forças que atuam e servem de suporte a amplos efeitos de clivagem que atravessam o conjunto da cultura fitness.

Foucault (1984) alerta que os sujeitos se produzem tanto por mecanismos de objetivação quanto pelos de subjetivação. Os modos de objetivação operam por meio da produção de saberes, como, por exemplo, os decorrentes da medicina, da fisiologia do exercício, que conferem um status de cientificidade à prática de exercícios físicos. Por outro lado, entendemos que a subjetivação decorre das orientações provenientes da cultura fitness, dos modos microfísicos de como tal cultura, com base em seus discursos, ensina modos de ser, de conviver e de relacionar-se com os outros por meio do culto ao corpo. Por conseguinte, objetivação e subjetivação são processos que podem ser entendidos como relacionais (FOUCAULT, 2004b).

Portanto, o desenvolvimento muscular posiciona discursivamente o sujeito, conferindoIhe características sociais de "bravura, honra e tenacidade" (CORBIN, 2008, p. 185). Há um aparato discursivo-cultural que enaltece os corpos fortes, energéticos, tonificados, firmes, objetivando e subjetivando os sujeitos. Por isso, entendemos que esse duplo movimento é uma marca importante para discutirmos a emergência da cultura do fitness, já que apresentam efeitos de sentido que fomentam a imagem idealizada de um homem viril e dominador.

Desse modo, ser um sujeito detentor de um corpo sarado, que apresenta vitalidade e energia, é representativo da cultura do fitness. Esse fato tem caracterizado as sociedades ocidentais contemporâneas e marcado um status no qual existe um imperativo de que homens e mulheres cuidem e desenvolvam atleticamente os seus corpos.

Assim, ressaltamos que a popularidade dos discursos sobre a cultura do fitness se estrutura, por um lado, pela cientificidade da produção discursiva da saúde e, por outro, pela produção discursiva da beleza e da estética (LANDA, 2012). Conforme argumenta Landa (2012, p. 226), a dimensão estética do "fitbody faz-se visível nas imagens dos corpos (feminino e masculino) exibidos nas diversas publicidades dos produtos do fitness". Ainda, Landa (2012) afirma que a cultura do fitness se associa ao plano discursivo da saúde, utilizando argumentos de que o treino muscular/corporal colabora para "um estilo de vida saudável". O treino muscular aparece como uma medida preventiva para contra-atacar as limitações da saúde, de forma que isso se replica como conhecimento de domínio público. As práticas dessas atividades prometem reduzir doenças, assim como aumentar a qualidade de vida e estendê-la por um maior número de anos.

De outro lado, a cultura do fitness alia-se ao plano discursivo da produção de beleza e da estética corporal, adquirida mediante trabalho corporal via musculação, e da produção de um corpo em forma (o fitbody). Esse sentimento de produção da estética colabora para 0 crescimento e divulgação de determinados elementos da cultura do fitness, pois todos podem sentir-se bonitos e adequados a determinados padrões, já que as "corporalidades de milhões de mulheres e homens aparecem confrontadas, de modo contínuo, com iconografias e histórias que interpelam o estar em forma e ter um corpo tonificado" (LANDA, 2012, p. 224).

Com base no exposto, inferimos que há a construção de uma dimensão fitness como uma produção simbólica de identidades. Ser fitness está vinculado a uma rede flexível e mutável de poder de natureza biopolítica, ligada com os jogos de produção de vida. Trata-se de um tipo de saber que se efetiva, sobretudo, a partir do corpo como capital (LANDA, 2012), de um conjunto de produtos e serviços diferenciados. 
Por esse motivo, a cultura do fitness passa a ser vista como um investimento, como um modo de vida que reverberará em visibilidade. Passa a ser tratada, também, como um produto do mercado contemporâneo relacionado diretamente à manutenção de uma vida saudável. Nesse sentido, o consumo da imagem de um corpo atlético vincula-se com questões relacionadas à vida (LIPOVETSY, 2004). Os corpos tornam-se representantes das posições que os sujeitos podem assumir, marcando posições identitárias. Para Lipovetsky (2004), os corpos emitem sinais que permitem aos sujeitos vestir-se e desvestir-se de identidades, conforme os contextos em que estão inseridos.

A título de ilustração, pensemos, por exemplo, nos produtos da cultura do fitness como artefatos simbólicos que têm ajudado a construir identidades, nas quais os corpos e seus adornos são relevantes para as pessoas se comunicarem umas com as outras. A cultura, então, vai suprir o mundo de significados, e estes serão transferidos para os objetos, criando manifestações culturais mais abrangentes (LIPOVETSKY, 2004). Passa-se a consumir a simbologia social apresentada pela cultura do fitness. Por isso, vemos o consumo como um meio de expressão cultural em que os significados culturais atribuídos aos objetos podem orientar as escolhas dos indivíduos e ajudá-los a criar e sustentar determinados estilos de vida.

Em tal direção, as escolhas de consumo baseiam-se nas necessidades funcionais dos objetos, bem como em seus significados simbólicos. Nesse âmbito, o consumo da cultura do fitness vem se construindo como uma importante fonte identitária que localiza os sujeitos no meio social. Afinal, o que o liberalismo introduz, como aponta Foucault (2008a, p. 30), é a formação de sujeitos não como "súditos obedientes ou indóceis, mas como indivíduos ligados a uma naturalidade econômica, em que sua longevidade, sua saúde, sua maneira de se comportar, se encontram relacionados com processos econômicos".

Corroborando o argumento exposto pelo filósofo, Jaeger e Goellner (2011) consideram que a cultura do fitness vem se constituindo, afirmando e atualizando, isto é, ela se multiplica e se reinventa para manter-se viva no campo econômico. De acordo com as autoras, existe uma proliferação de produtos direcionados ao "mercado do músculo", o qual coloca em jogo as produções corporais, potencializando algumas feminilidades e masculinidades em detrimento de outras.

Os praticantes do esporte fisiculturismo, e aqui pensamos nos adeptos das práticas da cultura do fitness, ao produzirem novos corpos, "comprovam que, o corpo não é um destino, tampouco uma linha divisória, mas uma possibilidade e uma escolha em favor de um ponto de apego móvel e momentâneo" (JAEGER; GOELLNER, 2011, p. 973). Isso evidencia que adeptos da cultura do fitness são subjetivados por verdades arquitetadas por discursos que produzem efeitos de sentido sobre suas vidas.

\section{ALINHAVOS DE UMA SÍNTESE (IN)CONCLUSIVA}

Na perspectiva de finalizar este artigo, indagamos: como a cultura do fitness se difundiu e se popularizou em um campo que antes era restrito à área da Educação Física? Nesse sentido, evidenciamos que a cultura do fitness se desenvolveu primeiramente na área da fisiologia do exercício, do esporte, da Educação Física - treinamento -, e hoje se estende a outros âmbitos e campos do conhecimento. Vemos a emergência de um novo estilo de vida em expansão - uma espécie de governamento da vida pelo fitness. 
Desse modo, compreendemos que a "vida fitness" ganhou força e visibilidade no século XXI, o que é comprovado pelo espraiamento dos discursos fitness em diferentes campos da vida cotidiana. Assim, um determinado modo de vida é produzido por saberes atribuídos à cultura do fitness como um valor de verdade. Para Foucault (2004b, p. 11), tal verdade se centra nas formas dos discursos científicos e nas instituições que vão produzi-la; ela está submetida "a uma constante incitação econômica e política (necessidade de verdade tanto para a produção econômica, quanto para o poder político)".

Nessa direção, os discursos da vida fitness constituem-se por meio de diferentes enunciados e ganham sustentação ao cruzarem com o dispositivo pedagógico da mídia (FISCHER, 2001) e com os dispositivos da economia e do consumo. Em suma, existe uma política, uma trama discursiva na qual se articulam diferentes elementos da cultura do fitness, colocando-os em funcionamento. Esses elementos, no decorrer do tempo, mudam de posição e rearticulam-se, pois a mídia reafirma certas "verdades", fazendo funcionar um jogo que incita os sujeitos a olharem para si e para os outros e a se constituírem a partir de parâmetros que Ihes são apresentados.

A esse respeito, destacamos que, na contemporaneidade, o "ser fitness" tornou-se moeda forte. Como aponta Foucault (2004b), as relações de saber constituem um padrão de verdade que produz sujeitos, bem como consolida e demarca certos campos econômicos. Pensando-se na ordem do saber, como no caso da cultura do fitness, esta promove uma nova "economia política do discurso fitness" na contemporaneidade. O desenvolvimento do sistema capitalista e de consumo levou a uma reconfiguração geral da vida, valendo-se do processo de politização da vida (biopoder), o qual converte os corpos no "lugar da moral, [no] seu fundamento último" (ORTEGA, 2003, p. 67).

Portanto, ao retomarmos a pergunta inicial - quais são as condições de emergência do espraiamento da cultura do fitness? -, salientamos que há uma repetição, uma ampliação dos discursos fitness, os quais convocam os sujeitos a participarem dessa posição ativa e dessa determinada maneira de consumir. Tem-se, assim, a constituição de certas verdades sobre a condição de ser fitness e a objetivação e subjetivação de um sujeito que vai se produzir na enunciabilidade disposta por essa política discursiva do fitness.

A emergência dessa cultura do fitness faz-nos pensar como os sujeitos são acionados e constituídos por uma rede discursiva articulada em torno da problemática da vida fitness que acomete o século XXI e que, por meio de uma rede de discursos, produz um novo ethos para os sujeitos. Tal produção discursiva opera com ditos que chamamos de posições identitárias, conferindo características de uma vida com mais vitalidade. Na constituição desse novo ethos, aprendemos a construir nossas vidas a partir do paradigma de natureza biopolítica que se associa à cultura do fitness. Certamente, esse novo ethos decorrente do fitness inaugura uma espiral virtualmente interminável de ampliação, na qual os sujeitos são responsabilizados pela gestão de seus corpos, produzindo-se um campo continuamente aberto para a construção de novos problemas e um mercado de novas soluções.

Por fim, destacamos que, no decorrer do artigo, tivemos a pretensão de evidenciar o espraiamento dos discursos sobre a cultura do fitness, intento que sem dúvida colaborará para novas reflexões a respeito do tema. Então, para finalizar, propomos o desafio de que continuemos a problematizar os discursos que nos produzem enquanto sujeitos do tempo presente, sejam esses derivados da cultura do fitness ou ainda de outras ordens. 


\section{REFERÊNCIAS}

BRACHTVOGEL, Caterine de Moura A cultura fitness nos memes: performances de gênero. 2017. 105 f. Dissertação (Mestrado em Educação nas Ciências) - Programa de Pós-Graduação em Educação nas Ciências, Universidade Regional do Noroeste do Estado do Rio Grande do Sul, ljuí, 2017.

CORBIN, Alain. Prazer e dor: no coração da cultura somática. In: CORBIN, Alain; COURTINE, Jean-Jacques; VIGARELLO, Georges (Orgs.). História do corpo: da revolução à grande guerra. Petrópolis: Vozes, 2008. v. 2. p. 1-11.

COURTINE, Jean-Jacques. Stakhanovistas do narcisismo: body-building e puritanismo ostentatório na cultura americana do corpo. In: SANT'ANNA, Denise Bernuzzi de (Org.). Políticas do corpo. São Paulo: Estação Liberdade, 1995. p. 81-114.

ESPRAIAR. In: DICIONÁRIO DO AURÉLIO. Disponível em: <https://dicionariodoaurelio.com/ espraiar>. Acesso em: 10 mar. 2018.

FISCHER, Rosa Maria. Foucault e análise do discurso em educação. Cadernos de Pesquisa, n. 114, p. 197-223, nov. 2001. Disponível em: <http://www.scielo.br/pdf/cp/n114/a09n114.pdf>. Acesso em: 07 jan. 2016.

FOUCAULT, Michel. A Ordem do Discurso. São Paulo: Edições Loyola, 2004a.

FOUCAULT, Michel. Em defesa da sociedade. São Paulo: Martins Fontes, 2000.

FOUCAULT, Michel. História da Sexualidade I: a vontade de saber. Rio de Janeiro: Edições Graal, 1988.

FOUCAULT, Michel. História da Sexualidade II: o uso dos prazeres. Rio de Janeiro: Graal, 1984.

FOUCAULT, Michel. Microfísica do poder. Rio de Janeiro: Edições Graal, 1979.

FOUCAULT, Michel. Microfísica do poder. Rio de Janeiro: Graal, 2004b.

FOUCAULT, Michel. Nascimento da Biopolítica. São Paulo: Martins Fontes, 2008a.

FOUCAULT, Michel. Resumo dos Cursos do Collège de France (1970-1982). Rio de Janeiro: Jorge Zahar Editor, 1997.

FOUCAULT, Michel. Segurança, território e população. São Paulo: Martins Fontes, 2008b.

FURTADO, Roberto Pereira. Do fitness ao wellness: os três estágios de desenvolvimento das academias de ginástica. Pensar a Prática, v. 12, n. 1, p. 1-11, jan./abr. 2009. Disponível em: <https://www.revistas.ufg.br/fef/article/view/4862>. Acesso em: 10 mar. 2018.

JAEGER, Angelita Alice; GOELLNER, Silvana Vilodre. O músculo estraga a mulher? A produção de feminilidades no Fisiculturismo. Estudos Feministas, v. 19, n. 3, p. 955-975, set./dez. 2011. Disponível em: <http://www.scielo.br/scielo.php?pid=S0104-026X2011000300016\&script=sci abstract\&tlng=pt>. Acesso em: 10 mar. 2018.

LANDA, María Inés. Os corpos da liderança: as tramas da ficção do dispositivo cultural do Fitness. Dossiê Cadernos Cedes, v. 32, n. 87, p. 223-233, maio/ago. 2012. Disponível em: <http://www.scielo.br/pdf/ccedes/v32n87/08>. Acesso em: 18 mar. 2016. 
LIPOVETSKY, Gilles. Os tempos hipermodernos. São Paulo: Barcarolla, 2004.

LIPOVETSKY, Gilles; SERROY, Jean. A cultura-mundo, respostas a uma sociedade desorientada. São Paulo: Companhia das Letras, 2011.

ORTEGA, F. Práticas de ascese corporal e constituição de bioidentidades. Cadernos Saúde Coletiva, v. 11, n. 1, p. 59-77, 2003. Disponível em: <http://www.cadernos.iesc.ufrj.br/cadernos/ images/csc/2003 1/artigos/2003 1\%20FOrtega.pdf>. Acesso em: 10 mar. 2018.

SABINO, Cesar. Os Marombeiros: construção de corpo e gênero em academias de musculação. 2000. 198 f. Dissertação (Mestrado em Sociologia e Antropologia) - Programa de Pós-Graduação em Sociologia e Antropologia, Universidade Federal do Rio de Janeiro, Rio de Janeiro, 2000.

TURNER, Brian. 0 corpo e sociedade. Londres: Sage Publications, 2004.

VARELLA, Dráuzio. Músculos fracos: o corpo humano não foi selecionado para viver mais de 20 ou 30 anos. Jornal Zero Hora, Caderno Vida, 5 de agosto, 2017.

VIGARELLO, Georges. Treinar. In: CORBIN, Alain; COURTINE, Jean-Jacques; VIGARELLO, Georges (Orgs.). História do Corpo: as mutações do olhar: o século XX. Petrópolis: Vozes, 2008. p. $197-250$. 